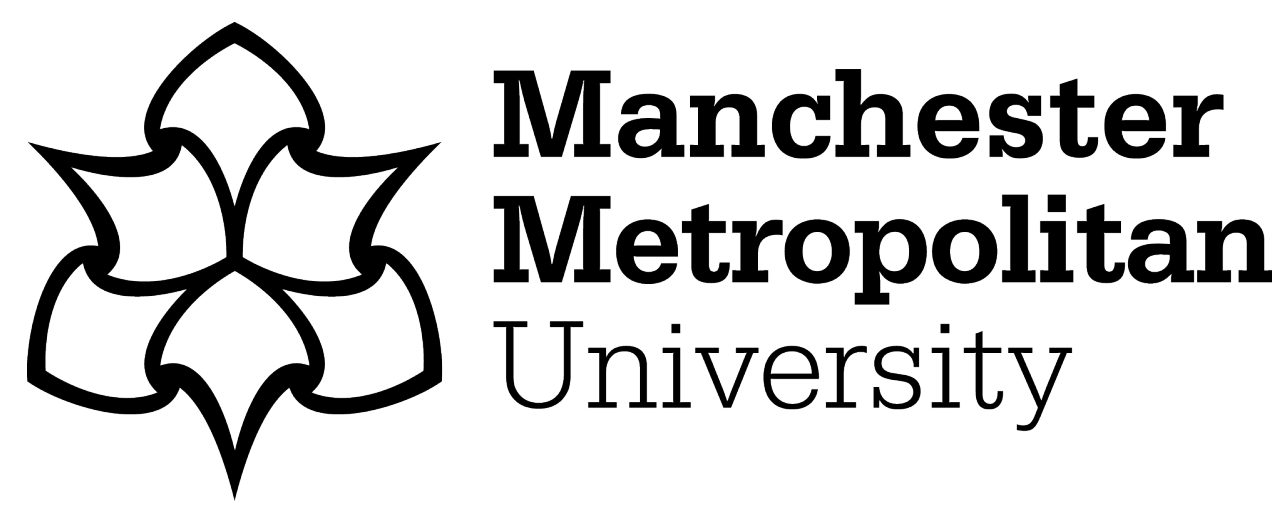

Ayad Jaber, Zuha, Jabbar Abdul-Zahra Al-Hmedat, Sattar, Hameed, Sarmad Adel, Al-Nasrawi, Suhad Jabbar Hamed, Aljdaimi, Abtesam Imhemed and Haider, Julfikar ORCID logoORCID: https://orcid.org/0000-0001-7010-8285 (2020) Effect of autoclave sterilisation and heat activated sodium hypochlorite irrigation on the performance of nickel-titanium rotary files against cyclic fatigue. Advances in Materials and Processing Technologies. pp. 1-13. ISSN 2374-068X

Downloaded from: https://e-space.mmu.ac.uk/626901/

Version: Accepted Version

Publisher: Informa UK Limited

DOI: https://doi.org/10.1080/2374068x.2020.1848309

Please cite the published version 


\title{
Effect of autoclave sterilisation and heat activated sodium hypochlorite irrigation on the performance of nickel-titanium rotary files against cyclic fatigue
}

\author{
Zuha Ayad Jaber, Sattar Jabbar Abdul-Zahra Al-Hmedat, Sarmad Adel \\ Hameed, Suhad Jabbar Hamed Al-Nasrawi , Abtesam Imhemed Aljdaimi \& \\ Julfikar Haider
}

To cite this article: Zuha Ayad Jaber, Sattar Jabbar Abdul-Zahra Al-Hmedat, Sarmad Adel Hameed, Suhad Jabbar Hamed Al-Nasrawi , Abtesam Imhemed Aljdaimi \& Julfikar Haider (2020): Effect of autoclave sterilisation and heat activated sodium hypochlorite irrigation on the performance of nickel-titanium rotary files against cyclic fatigue, Advances in Materials and Processing Technologies, DOI: 10.1080/2374068X.2020.1848309

To link to this article: https://doi.org/10.1080/2374068X.2020.1848309 


\title{
Effect of autoclave sterilisation and heat activated sodium hypochlorite irrigation on the performance of nickel-titanium rotary files against cyclic fatigue
}

\author{
Zuha Ayad Jabera, Sattar Jabbar Abdul-Zahra Al-Hmedat ${ }^{\mathrm{a}}$, Sarmad Adel Hameed ${ }^{\mathrm{b}}$, \\ Suhad Jabbar Hamed Al-Nasrawi ${ }^{a}$, Abtesam Imhemed Aljdaimic and Julfikar Haider ${ }^{\mathrm{c}}$ \\ aDepartment of Conservative Dentistry, Faculty of Dentistry, University of Kufa, Najaf, Iraq; ${ }^{\text {bDepartment of }}$ \\ Oral Medicine and oral Pathology, Faculty of Dentistry, University of Kufa, Al - Najaf, Iraq; 'College of \\ Dentistry and Oral Surgery, Alasmarya University, Libya; ${ }^{d}$ Department of Engineering, Manchester \\ Metropolitan University, Manchester, UK
}

\begin{abstract}
The present study aims to assess the impact of heatactivated sodium hypochlorite $(\mathrm{NaOCl})$ and/or autoclave sterilisation on the cyclic fatigue resistance (CFR) of heat-treated nickeltitanium rotary files used in root canal treatment. The CFR of One Curve $(O C)$ files was evaluated under the following conditions: as received (Group 1; control), immersion in $\mathrm{NaOCl}$ at $23 \pm 1^{\circ} \mathrm{C}$ (Group 2), immersion in $\mathrm{NaOCl}$ at $60 \pm 1^{\circ} \mathrm{C}$ (Group 3), autoclave sterilisation at $1351^{\circ} \mathrm{C}$ (Group 4), combined treatment of autoclave sterilisation and immersion in $\mathrm{NaOCl}$ at $23 \pm 1{ }^{\circ} \mathrm{C}$ (Group 5), and combined treatment of autoclave sterilisation and immersion in $\mathrm{NaOCl}$ at $60 \pm 1^{\circ} \mathrm{C}$ (Group 6). A simulated root canal in a zirconia block was utilised to test the performance of the files. All the types of treatments resulted in significant reductions in fracture resistance of the $\mathrm{OC}$ files. Immersion of the files in $\mathrm{NaOCl}$ at $23^{\circ} \mathrm{C}$ revealed the smallest reduction, while combined treatment of autoclaving and immersion in $\mathrm{NaOCl}$ at $60^{\circ} \mathrm{C}$ caused the greatest reduction. Autoclave sterilisation or exposure of OC files to $2.5 \% \mathrm{NaOCl}$ adversely affect the cyclic fatigue life and increasing solution temperature or combined treatment caused additionally significant reduction in CFR.
\end{abstract}

\section{ARTICLE HISTORY}

Accepted 7 November 2020

\section{KEYWORDS}

End od ontic nickel-titanium file; cyclic Fatigue; One Curve file; a utoclave; sodium hypochlorite; heat activation

\section{Introduction}

One of the fundamental steps in the root canal treatment is the cleaning and shaping of the root canal [1]. The use of NiTi rotary files provided faster and more effective canal preparation than the conventional files [2]. In spite of these advantages, NiTi files are susceptible to deformations and fractures, contributing negatively to the prognosis of the treatment [3]. To get over these downsides, enhancements in instrument design, heat treatment process, and the introduction of innovative NiTi alloys with superior mechanical properties have been offered [2]. One Curve is one of these improved products. It is a heat-treated NiTi rotary file adapting $\mathrm{C}$ wire technology with superelastic properties 
enables full-length preparation of the canal with a single file. One Curve, a smart, competent, and conservative NiTi file, has increased flexibility and separation resistance, precise taper, and diameter for an ultimate canal shaping that meets standards of an optimised cleaning and shaping, and preserves the original anatomy of the root canal $[4,5]$.

In conjunction with the work of intracanal instrument, effective cleaning of the root canal relies on irrigating solutions. It is recommended to use solutions having bacteriostatic or bactericidal activity with tissue-dissolving capabilities to facilitate the root canal space debridement [1]. Sodium hypochlorite is the most preferred irrigant due to its excellent antibacterial property and capability of successfully dissolving organic components of the dentine, biofilm, vital pulp tissue, and necrotic tissue. Moreover, it is inexpensive, readily available with a relatively long shelf life [6,7]. However, $\mathrm{NaOCl}$ induced corrosion is a threat that might restrict the resistance of a file to fatigue fracture, and it happens during root canal preparation when a file comes in contact with the $\mathrm{NaOCl}$ solution. Pits and surface defects are generated, acting as a focal point for the propagation of fatigue failure [8].

Several studies examined the impact of $\mathrm{NaOCl}$ on the CFR of the NiTi rotary files, resulting in controversial findings [9-15]. A number of studies have reported a reduction in CFR of NiTi files when contacted with $\mathrm{NaOCl}[8,16,17]$. On the other hand, Pedulla et al. $[15,18]$ stated that file exposure to $\mathrm{NaOCl}$ solution did not reduce CFR of the heattreated NiTi instruments (Twisted Files, Hyflex CM, Reciproc R25, Wave one Primary, and Pro Taper F2). In relation to OC files, Ertugrul [19] demonstrated that the 2.5\% $\mathrm{NaOCl}$ at $35^{\circ} \mathrm{C}$ caused a non-significant reduction in the CFR, where the OC revealed higher CFR than One shape and ProTaper Next types of files.

One of the currently developed strategies to improve $\mathrm{NaOCl}$ effectiveness is the preheating of low concentration solutions in order to facilitate the dissolution of the organic and inorganic tissues and to disinfect the whole canal system. The heating of $\mathrm{NaOCl}$ irrigating solution plays a central role in promoting an effective cleaning of the root canal space [20-22]. Heat-activation of the solution to $60^{\circ} \mathrm{C}-70^{\circ} \mathrm{C}$ before irrigation is more efficient [23]. Huang et al. [24] demonstrated that $5.25 \% \mathrm{NaOCl}$ did not affect the CFR of NiTi files, but heat activation of the solution caused a significant reduction in CFR as a result of the negative influence on the metallurgical properties of the NiTi files.

Sterilisation of NiTi instruments is an important requirement to avoid crosscontamination [25]. Autoclaving has been considered as the most efficient sterilisation method for endodontic files [26]. The ratio of nickel and titanium in NiTi alloy is nearly equiatomic, with about $56 \% \mathrm{Ni}$ and $44 \% \mathrm{Ti}$ [27]. With these shares, two temperaturedependent crystalline structures identified are austenite and martensite phases [15]. In the austenitic phase, the alloy is hard, rigid and has excellent superelastic properties. In contrast, in its martensitic phase, the alloy is soft, ductile, and easily deformed with shape memory effect [28]. At ambient temperature, many files are in the martensitic state of material or at least lower than the austenite state; therefore, they are still rather flexible $[15,29,30]$. As the NiTi properties are greatly affected by thermomechanical processing, an added heat during processing such as autoclave sterilisation can influence the mechanical properties of these instruments leading to fatigue failure. This concern has been highlighted in previous publications that presented the influence of autoclave sterilisation on the cyclic fatigue life of NiTi files [12,30-32]. However, these findings 
remained controversial, and the outcomes from the other published studies varied from increasing [30-32], decreasing [15,33] or not affecting [15,31-33] the cyclic fatigue strength of the heat-treated NiTi files.

The heat-treated NiTi rotary files might be subjected to post-manufacturing thermal challenges because of autoclave sterilisation or contacting with disinfecting chemicals at different temperatures. Literature research showed that no study examined the effect of heat-activated $\mathrm{NaOCl}$ and/or autoclave sterilisation on the CFR of One Curve file. The purpose of the current study was to understand the individual and combined impacts of heat-activated $\mathrm{NaOCl}$ immersion and autoclave sterilisation on the CFR of OC files. The null hypothesis was that autoclave sterilisation and/or heat activation of $\mathrm{NaOCl}$ does not influence the fracture resistance of the $\mathrm{OC}$ files.

\section{Materials and methods}

\subsection{File samples and preparation}

Thirty-six One Curve (OC; Micro-Mega, Besançon, France) heat-treated NiTi rotary endodontic files with a size of 25 and tapering of 0.06 were selected for the fatigue resistance test. The files were initially observed at $20 \times$ magnification to ensure that they were defect-free. According to the type of treatment, they were allocated into six groups $(n=6)$. The file conditions in the groups are presented in Table 1.

Dynamic immersion of the files was conducted by attaching them to an endodontic contra-angle handpiece motorised by a torque-controlled electric motor (X-smart, Dentsply Maillefer, Ballaigues, Switzerland), placing into a container containing $10 \mathrm{ml}$ of $2.5 \% \mathrm{NaOCl}$ at $23^{\circ} \mathrm{C}$ or $60^{\circ} \mathrm{C}$ (according to the experimental groups) and freely rotated in the container without the file shaft contacting the $\mathrm{NaOCl}$ solution. Throughout the operation of the files, the solution temperature was observed with a digital thermostat (Elimko, Elimko Electronics Manufacturing, Ankara, Turkey). Following rotation in a continuous clockwise mode for 10 minutes at a speed of $350 \mathrm{rpm}$, the file was removed from the container, thoroughly rinsed with distilled water and dried to get rid of any effect from the $\mathrm{NaOCl}$ solution. For autoclaving, the files were placed in a sealed autoclave pouch (Ningbo Jiangbei Woson Medical Instrument Co. Ltd. Ningbo, China).

Table 1. Experimental groups and conditions.

\begin{tabular}{|c|c|}
\hline Group number & File treatment condition \\
\hline $\begin{array}{l}\text { Group } 1 \text { (control } \\
\text { group) }\end{array}$ & As received \\
\hline Group 2 & $\begin{array}{l}\text { Dynamically immersed (rotated freely in the solution) in } 10 \mathrm{ml} \text { of } 2.5 \% \mathrm{NaOCl} \text { solution for } 5 \mathrm{~min} \\
\text { at } 23 \pm 1{ }^{\circ} \mathrm{C}\end{array}$ \\
\hline Group 3 & Dynamically immersed in $10 \mathrm{ml}$ of $2.5 \% \mathrm{NaOCl}$ solution for 5 min at $60 \pm 1^{\circ} \mathrm{C}$ \\
\hline Group 4 & Autoclaved at $135^{\circ} \mathrm{C}$ for $27 \mathrm{~min}$ ( $18 \mathrm{~min}$ for sterilisation and 9 min for drying) \\
\hline Group 5 & $\begin{array}{l}\text { Treated with a combination of autoclaving and dynamically immersing in } 10 \mathrm{ml} \text { of } 2.5 \% \mathrm{NaOCl} \\
\text { solution for } 5 \mathrm{~min} \text { at } 23 \pm 1^{\circ} \mathrm{C} \text {. }\end{array}$ \\
\hline Group 6 & $\begin{array}{l}\text { Treated with a combination of autoclaving and dynamically immersing in } 10 \mathrm{ml} \text { of } 2.5 \% \mathrm{NaOCl} \\
\text { solution for } 5 \mathrm{~min} \text { at } 60 \pm 1^{\circ} \mathrm{C} \text {. }\end{array}$ \\
\hline
\end{tabular}




\subsection{Cyclic fatigue testing}

CFR of the treated files from different groups was assessed using an experimental set-up comprised a motorised handpiece and an artificial canal as shown in Figure 1. The artificial canal was created inside a block of zirconia with $0.6 \mathrm{~mm}$ apical diameter, $6.06 \mathrm{~mm}$ radius, and $45^{\circ}$ curvature angle. The canal curvature started approximately $2.5 \mathrm{~mm}$ from the canal tip and the maximum curvature was about $5.5 \mathrm{~mm}$ from the tip. It was prepared on the pre-sintering zirconia blocks, then sintering the zirconia blocks in a sintering oven (Vita Zyrcomat, Vita Zahnfabrik Germany) for $1 \mathrm{~h}$ at $1500^{\circ} \mathrm{C}$ to obtain the full strength of zirconia [34].

To avoid slipping out of the files, and to allow good observation of the files, the simulated canal was covered with a transparent glass plate. In order to ensure a standardised testing, the handpiece was fixed and thus avoiding any inconsistency that might be caused by the manual operation. Following the manufacturer's recommendation, the files were rotated at a full clockwise rotation using the handpiece at $350 \mathrm{rpm}$. The rotation of the file in the canal was visually observed using endodontic loup (Quick Loupes, Univet, Rezzato, Italy) to determine the fracture moment. Following each file change, the artificial canal was irrigated with oil to limit the effect of friction between the instrument and the canal walls. The time-to-fracture was counted with a $1 / 100$ s chronometer. The number of cycles to failure (NCF) is defined by equation 1 .

$$
N C F=t \times N
$$

where $\mathrm{t}$ is the time recorded to fracture a file ( $\mathrm{min})$ and $\mathrm{N}$ is the number of rotations per minute of the files. The obtained NCF data $(n=36)$ from each group were averaged to compute the mean value. The lengths of the resulting fractured fragments were measured using a digital caliper (Mitutoyo, Kawasaki, Japan).

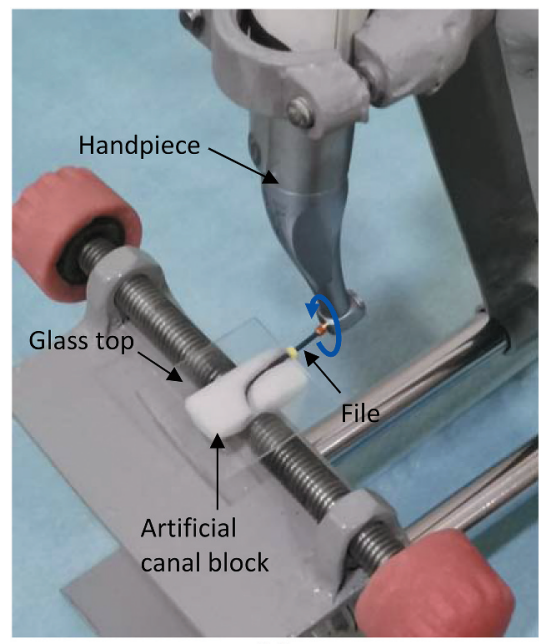

(a)

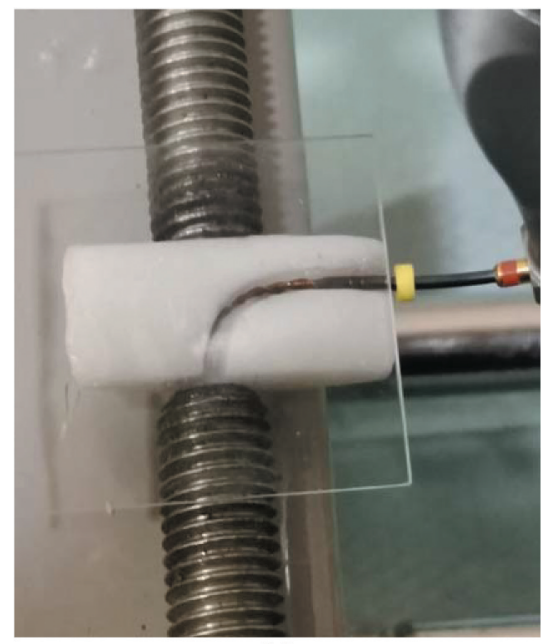

(b)

Figure 1. (a) Experimental set-up for cyclic fatigue testing of end od onticfiles and (b) Zirconia block with an artificial canal. 
Table 2. Mean (standard deviation) of the number of rotations to failure (NCF) and length of file fractured fragments $(\mathrm{mm})$.

\begin{tabular}{lcc}
\hline Groups & NCF (SD) & Fragment length, mm (SD) \\
\hline Group 1: Control (as received) & $1191.94(10.22)^{\mathrm{a}}$ & $2.58(0.03)^{\mathrm{a}}$ \\
Group 2: $2.5 \% \mathrm{NaOCl}$ at $23^{\circ} \mathrm{C}$ & $1120.97(10.05)^{\mathrm{b}}$ & $2.97(0.01)^{\mathrm{b}}$ \\
Group 3: $2.5 \% \mathrm{NaOCl}$ at $60^{\circ} \mathrm{C}$ & $987.78(10.22)^{\mathrm{c}}$ & $3.63(0.02)^{\mathrm{c}}$ \\
Group 4: Autoclave at $135^{\circ} \mathrm{C}$ & $1050.19(0.10)^{\mathrm{d}}$ & $2.66(0.23)^{\mathrm{a}}$ \\
Group 5: Autoclave \& $2.5 \% \mathrm{NaOCl}$ at $23^{\circ} \mathrm{C}$ & $994.58(6.12)^{\mathrm{c}}$ & $3.89(0.023)^{\mathrm{c}}$ \\
Group 6: Autoclave \& $2.5 \% \mathrm{NaOCl}$ at $60^{\circ} \mathrm{C}$ & $874.03(10.05)^{\mathrm{e}}$ & $4.19(0.02)^{\mathrm{d}}$ \\
\hline
\end{tabular}

Different superscript letters within a column indicate statistically significant difference between groups $(P \leq 0.05)$ and same letter in two groups does not indicate any significant difference $(P \geq 0.05)$

\subsection{Statistical analysis}

As the Shapiro-Wilks test indicated the normal distribution of the data of NCF and the fragment length. One-Way ANOVA and Bonferroni test were performed to decide any statistically significant differences between the groups using SPSS software version 22.0 (IBM Corp., Armonk, US). All testing was performed at a confidence level of 95\%, and $P \leq 0.05$.

\section{Results}

As presented in Table 2, in comparison to the control group, high statistically significant differences in NCF were recorded for all other groups. The control group recorded the highest NCF (1191.94), while the group from the combined treatment of autoclaving and heat-activated $\mathrm{NaOCl}$ recorded the lowest NCF (874.03). Also, statistically significant differences in NCF were recorded between the groups except between Group 3 (987.78) and Group 5 (994.58). The NCF values as a result of different treatments on the files produced the following ascending order: Autoclaving $+\mathrm{NaOCl}$ at $60^{\circ} \mathrm{C}<\mathrm{NaOCl}$ at $60^{\circ} \mathrm{C}$ $<$ Autoclaving $+\mathrm{NaOCl}$ at $23^{\circ} \mathrm{C}<$ Autoclaving $<\mathrm{NaOCl}$ at $23^{\circ} \mathrm{C}<$ Control. The highest percentage of NCF reduction in the Group 6 compared to the control group was $26.67 \%$.

Regarding the length of the fractured fragment, the control group recorded the shortest fracture fragments, while the combined treatment of autoclaving and $\mathrm{NaOCl}$ at $60^{\circ} \mathrm{C}$ recorded the longest fragments. In comparison with the control group, all other groups showed significant difference except Group 4. Significant statistical differences were detected between the groups except between Group 3 and Group 5. Similar trend was also observed in NCF. The fractured lengths measured from different groups after fatigue testing produced the following descending order: Autoclaving $+\mathrm{NaOCl}$ at $60^{\circ} \mathrm{C}>$ Autoclaving $+\mathrm{NaOCl}$ at $23^{\circ} \mathrm{C}>\mathrm{NaOCl}$ at $60^{\circ} \mathrm{C}>\mathrm{NaOCl}$ at $23^{\circ} \mathrm{C}>$ Autoclaving $>$ Control.

The results are also presented graphically in Figure 2. The relationship between the NCF and fracture length was clear except Group 4. For example, at the most harsh condition with a combined effect of autoclaving and immersing in $10 \mathrm{ml}$ of $2.5 \% \mathrm{NaOCl}$ solution for $5 \mathrm{~min}$ at $60^{\circ} \mathrm{C}$, the NCF values were the lowest whereas the fractured length was the highest in contrast to the opposite trend in the control group. The fragments from the corresponding files are presented in Figure 3. 


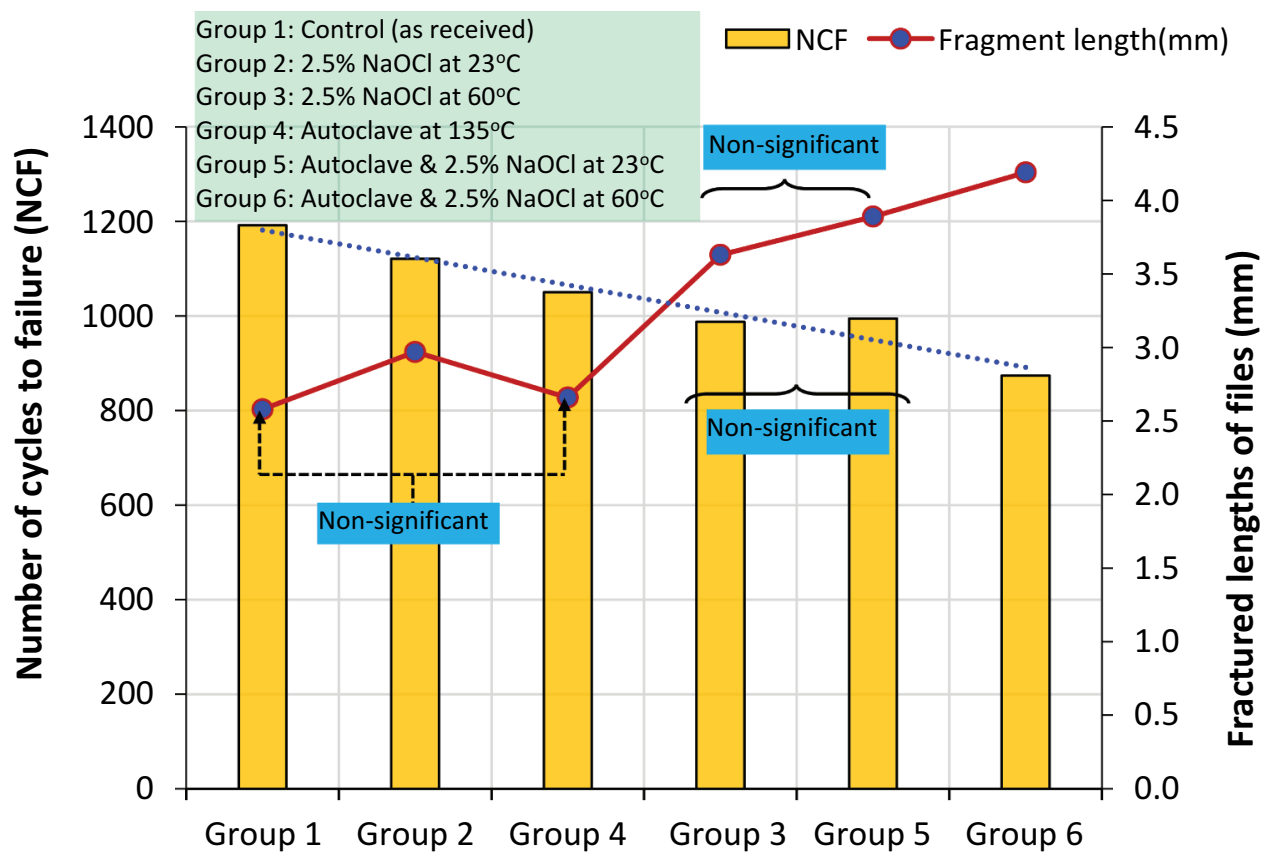

\section{Experimental groups}

Figure 2. Cyclic fatigue performance of one curve files under different treatment conditions.

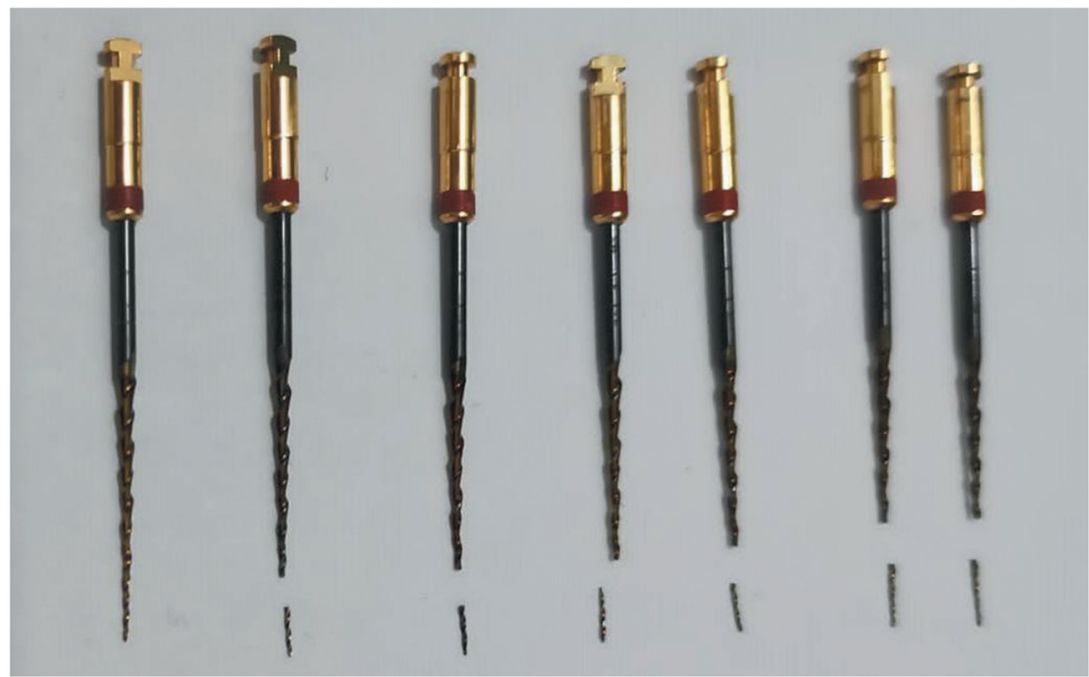

Figure 3. Files with broken fragments from each group and new file.

\section{Discussions}

High-performing instruments have been introduced for the preparation of the root canal, making the endodontic treatment easy and safe. As cyclic fatigue is one of the leading cause for the file fracture [35], it is worth to conduct cyclic fatigue tests on advanced 
single system NiTi files as they might undergo chemical [16], and/or thermal environments [26]. This study investigated the effects of these individuals (e.g., heat-activated $\mathrm{NaOCl}$ ) and their combined (e.g., autoclave sterilisation + heat-activated $\mathrm{NaOCl}$ ) environments on the cyclic fatigue resistance of OC endodontic file.

According to the outcomes of this study, the CFR of OC file was significantly affected by both individual and combined treatments with $2.5 \% \mathrm{NaOCl}$ at $23^{\circ} \mathrm{C}$, heat-activated $2.5 \% \mathrm{NaOCl}$ at $60^{\circ} \mathrm{C}$ or autoclave sterilisation. Therefore, the hypothesis was rejected.

The role of the irrigating solution is essential to guarantee the success of root canal treatment. Among the irrigation solution, $\mathrm{NaOCl}$ is the preferable irrigant, due to its promising antibacterial, pulp dissolution, and lubricating abilities [7]. It has been confirmed that the antibacterial efficiency of $\mathrm{NaOCl}$ is influenced by its concentration, volume, exposure time, and temperature [36]. Though high concentrations of $\mathrm{NaOCl}$ are required for the bacterial elimination [37-40], 2.5\% $\mathrm{NaOCl}$ is still the most preferable concentration utilised in endodontic procedures [41], avoiding the possible toxicity associated with the high concentration [21]. Thus, $2.5 \% \mathrm{NaOCl}$ was used in the current study. Regarding the contact time, $\mathrm{NaOCl}$ irrigation was ranged from 2 to $40 \mathrm{~min}$ [38-40,42]. Gulsahi et al. [43] stated that $5 \mathrm{~min}$ irrigation with $2.5 \% \mathrm{NaOCl}$ at $25^{\circ} \mathrm{C}$ was the most efficient. Therefore, the 5 min contact time was considered in the current study. In relation to the file immersion in the $\mathrm{NaOCl}$ solution, the shaft of the file was not immersed in the irrigant, simulating the clinical case in root canal preparation. This was also maintained to avoid the possible phenomena of galvanic corrosion [44].

The present result indicated that the autoclaving of the OC files caused a significant reduction in the CFR. Concerning similar studies conducted on other types of files, the current finding was in agreement with Pedulla et al. and Hilfer et al. [15,33] and disagreed with the findings by Plotino et al., Zhao et al. and Özyürek et al. [30-32]. The phase constitution of NiTi instruments at a particular temperature is crucial in defining their mechanical properties [45]. Therefore, the high temperature and the pressure of autoclaving might cause a change in the metallurgical properties, affecting the integrity and flexibility of the file. This could be attributed to the transition of the alloy from the martensitic phase to the stiffer austenitic phase, which was more susceptible to fatigue crack propagation [46].

The present study demonstrated an adverse effect of $2.5 \% \mathrm{NaOCl}$ irrigation on the CFR of OC files. That was in agreement with Abuhulaibah et al. [47] as they showed that 5 min file immersion in $2.5 \% \mathrm{NaOCl}$ at body temperature significantly lowered the resistance of the OC files for cyclic fatigue. On the other hand, the current results disagreed with that reported by Ertugrul [19]. In that study, although OC revealed higher CFR than One shape and ProTaper Next files, it had nonsignificantly reduced the CFR of the OC. However, the author used different experimental conditions such as during testing the file, and the artificial canal was immersed into a water bath containing the irrigation solution, where the file rotated till fracture. However, carrying out the test at intracanal temperature $\left(35^{\circ} \mathrm{C}\right)$ resulted in a significant reduction in the CFR of OC files compared with testing at ambient temperature [48].

According to the result of the present study, heating the $\mathrm{NaOCl}$ to $60^{\circ} \mathrm{C}$ caused a more dramatic reduction in the CFR. The adverse effect of the thermal activation came in accordance with Bedier et al. [49] as they demonstrated that high temperature of the 
irrigation solution (distilled water) had a reducing effect on the flexural CFR of the one (predecessor of OC) and two shape system of rotary endodontic instruments. The studies conducted by Demiral et al. [50], and Keles et al. [17] also supported the current results as the CFR of one-shape file system exposed to heat-activated $\mathrm{NaOCl}$ at $50^{\circ} \mathrm{C}$ showed a significant reduction. However, the same experimental condition caused a nonsignificant effect on the Reciproc Blue [17]. Although the study by Huang et al. [24] demonstrated that $5.25 \% \mathrm{NaOCl}$ did not have any influence on the CFR of the NiTi files, heat activation of the solution caused significant reduction, influencing the metallurgical properties of NiTi files. On the other hand, the current results were in contradiction with the study by Pedulla et al. [51] where they reported that $\mathrm{NaOCl}$ improved the CFR of OC, independent of the temperature applied $\left(20^{\circ} \mathrm{C}\right.$ and $\left.37^{\circ} \mathrm{C}\right)$. However, they applied different experimental settings having an artificial canal of a $60^{\circ}$ angle of curvature and a continuous flow of the irrigant in the artificial canal which resulted in a reduction in the volume of solution and the exposure period.

It has been recorded that $\mathrm{NaOCl}$ etches the NiTi instruments, removing nickel ions from the surface to form micro-holes [52]. This corrosive activity could create stress accumulation and crack propagation on the instrument. Thus, a contact between $\mathrm{NaOCl}$ and files might have an adverse impact on the mechanical integrity of NiTi instruments [16,53]. Thermal activation of the $\mathrm{NaOCl}$ causes an increase in the release of free available chlorine in the solution [54]. These molecules are accountable for the chlorinating and oxidising action [55]. The increased elaboration of the chlorine caused an increase in the corrosive ability of the solution. It was also recorded that the chlorine concentration increased the corrosion rate. Furthermore, the temperature plays a vital role in advancing the metal corrosion rate. The higher the temperature is, the higher the corrosion rate [56,57].

One of the key findings of the present study was that the combination of autoclaving and file immersion in $2.5 \% \mathrm{NaOCl}$ solution caused a more dramatic reduction in the CFR which was worst if the autoclaving followed by file immersion in heat-activated solution. Although in Bulem et al. [25] study, the combination of file immersion in $2.5 \% \mathrm{NaOCl}$ at $23^{\circ} \mathrm{C}$ followed by autoclaving reduced the CFR of ProFile, FlexMaster, Twisted File, MTWO, the differences were statistically not significant. In relation to other types of heat-treated NiTi files, Pedulla et al. [15] recorded a non-significant reduction in the CFR of Hyflex CM file even after repeating of the cycle of the combined treatment for 3 times, while Twisted files showed a significant decrease after the repeating of that cycle. However, the effect of combined treatment seemed to differ with a different type of files. File exposure to $\mathrm{NaOCl}$ after autoclave might increase the depth of the surface irregularity, enhancing fatigue propagation $[58,59]$. The processing conditions of the files during manufacturing and different thermal managements might have a vital effect on the performance of the files as NiTi is an alloy susceptible to both the thermal and mechanical stresses [30]. Exposure of the autoclaved file to heat-activated corrosive irrigant resulted in a further dramatic reduction in the CFR, reflecting the accumulative effect of cracking that caused by the autoclaving and the $\mathrm{NaOCl}$ induced corrosion which would be more aggressive as a result of the heat activation.

According to the result of the present study, the greater weakening of a file can be determined by the longer length of the fractured segment. It was observed that the instrument fractured at the site of maximum flexure within the curved canal where the 
high-stress concentration was expected. The length of the fractured fragments of the files was significantly influenced by the type of tested treatments. It was stated that small cross-section exhibit greater resistance to cyclic fatigue [60-62]. Therefore, after the exposure of the files to the tested challenges, the area of bigger file diameter (far from the apical) appeared to be more vulnerable to fracture.

One of the limitations of this study was that the clinical relevance was challenging to achieve. While performing the test on extracted teeth could simulate clinical situations, they were not anatomically standardised [63]. Thus, an artificial canal was utilised to rule out all the other variables other than the tested variables. For the same purpose of reducing the variable, oil had been used to lubricate the movement of the file inside the canal, reducing the effect of friction between the file and the canal walls. Therefore, as a future study, it is worthwhile to investigate the impact of intracanal lubricant on the CFR. Additional suggestions include investigating the effects of the tested conditions on other types of heat-treated NiTi files, and the effect of lower concentration $\mathrm{NaOCl}$ on the CFR of OC file to identify the minimum amount of concentration that does not significantly affect the CFR of the file. Microscopic analysis can be performed on the fractured specimens in the future to support the findings.

Usage of $\mathrm{OC}$ file in conjunction with intracanal irrigation with $2.5 \% \mathrm{NaOCl}$ at room temperature $\left(23^{\circ} \mathrm{C}\right)$ or heat-activated at $60^{\circ} \mathrm{C}$ and/or autoclaving significantly reduced the cyclic fatigue resistance of the $\mathrm{OC}$ endodontic file. Therefore, after canal irrigation with $\mathrm{NaOCl}$, it is advised, as a general clinical practice, to wash the canal with an inert solution such as distilled water or normal saline to avoid any adverse effect on the OC files contacting with the irrigant.

\section{Conclusions}

Within the limitations of the present study, it can be concluded that the CFR of the heated treated NiTi rotary files (OC) was adversely affected by the immersion in $2.5 \%$ $\mathrm{NaOCl}$ or one cycle autoclave sterilisation. A more significant reduction in the CFR caused by heat activation of the solution or combination of autoclaving with the immersion in the solution at room temperature. However, the drastic effect would have resulted from the combination of immersion in the heat-activation solution and the autoclaving.

\section{Acknowledgments}

The authors would like to thank Dr Hanan Dekan from Department of Physiology, Faculty of Dentistry, Jabir Bin Hayyan Medical University, Miss. Rafah Sattar Al-Hmedat for help in preparation for this research.

\section{Financial support and sponsorship}

The work did not receive any funding. 


\section{Disclosure statement}

There are no conflicts of interest.

\section{References}

[1] Torabinejad M, Walton R Endodontics: principles and practice. 4 ed. St Louis, Missouri: Saunders Elsevier. 2009.

[2] Cheung GS, Liu CS A retrospective study of endodontic treatment outcome between nickel-titanium rotary and stainless steel hand filing techniques. J Endod. 2009;35 (7):938-943.

[3] Iqbal MK, Kohli MR, Kim JS A retrospective clinical study of incidence of root canal instrument separation in an endodontics graduate program: a PennEndo database study. J Endod. 2006;32(11):1048-1052.

[4] D'Amario M, De Angelis F, Mancino M, et al. Canal shaping of different single-file systems in curved root canals. J Dental Sci. 2017;1(4):328-332.

[5] Kuzekanani M Nickel-Titanium rotary instruments: development of the single-file systems. J Int Soc Prev Community Dent. 2018;8(5):386.

[6] Hargreaves KM, Berman LH Cohen's pathways of the pulp expert consult: Elsevier Health Sciences; 2015.

[7] Poggio C, Arciola CR, Dagna A, et al. Antimicrobial activity of sodium hypochlorite-based irrigating solutions. Int J Artif Organs. 2010;33(9):654-659.

[8] Pedulla E, Grande NM, Plotino G, et al. Cyclic fatigue resistance of three different nickel-titanium instruments after immersion in sodium hypochlorite. J Endod. 2011;37 (8):1139-1142.

[9] Peters OA, Roehlike JO, Baumann MA Effect of immersion in sodium hypochlorite on torque and fatigue resistance of nickel-titanium instruments. J Endod. 2007;33(5):589-593.

[10] Pedullà E, Grande N, Plotino G, et al. Cyclic fatigue resistance of two reciprocating nickeltitanium instruments after immersion in sodium hypochlorite. Int Endod J. 2013;46 (2):155-159

[11] Dagna A, Beltrami R, Colombo M, et al. Cyclic fatigue resistance of three single-use NiTi instruments after immersion in sodium hypochlorite. Int J Experimental Dental Sci. 2014;3 (2):67.

[12] Champa C, Divya V, Srirekha A, et al. An analysis of cyclic fatigue resistance of reciprocating instruments in different canal curvatures after immersion in sodium hypochlorite and autoclaving: an in vitro study. J Conservative Dentistry: JCD. 2017;20(3):194.

[13] Alfawaz H, Alqedairi A, Alsharekh $\mathrm{H}$, et al. Effects of sodium hypochlorite concentration and temperature on the cyclic fatigue resistance of heat-treated nickel-titanium rotary instruments. J Endod. 2018;44(10):1563-1566.

[14] Palma PJ, Messias A, Cerqueira AR, et al. Cyclic fatigue resistance of three rotary file systems in a dynamic model after immersion in sodium hypochlorite. Odontology. 2019;107 (3):324-332.

[15] Pedullà E, Benites A, La Rosa GM, et al. Cyclic fatigue resistance of heat-treated nickel-titanium instruments after immersion in sodium hypochlorite and/or sterilization. J Endod. 2018;44(4):648-653.

[16] O'hoy P, Messer H, Palamara J The effect of cleaning procedures on fracture properties and corrosion of NiTi files. Int Endod J. 2003;36(11):724-732.

[17] Keles A, Ozyurek EU, Uyanik MO, et al. Effect of temperature of sodium hypochlorite on cyclic fatigue resistance of heat-treated reciprocating files. J Endod. 2019;45(2):205-208.

[18] Pedullà E, Franciosi G, Ounsi HF, et al. Cyclic fatigue resistance of nickel-titanium instruments after immersion in irrigant solutions with or without surfactants. J Endod. 2014;40 (8):1245-1249. 
[19] Ertuğrul İF Effect of sodium hypochlorite on the cyclic fatigue resistance: a scanning electron microscopy evaluation. Microsc Res Tech. 2019;82(12):2089-2094.

[20] Sirtes G, Waltimo T, Schaetzle M, et al. The effects of temperature on sodium hypochlorite short-term stability, pulp dissolution capacity, and antimicrobial efficacy. J Endod. 2005;31 (9):669-671.

[21] Spencer H, Ike V, Brennan P the use of sodium hypochlorite in endodontics-potential complications and their management. Br Dent J. 2007;202(9):555-559.

[22] Rossi-Fedele G, De Figueiredo JA Use of a bottle warmer to increase 4\% sodium hypochlorite tissue dissolution ability on bovine pulp. Australian Endodontic J. 2008;34 (1):39-42.

[23]. Dash T, Mohan R, Mannava Y, et al. Effect of storage temperature and heating on the concentration of available chlorine and $\mathrm{pH}$ of $2.5 \%$ sodium hypochlorite. Saudi Endodontic J. 2017;7(3):161-165.

[24] Huang X, Shen Y, Wei X, et al. Fatigue resistance of nickel-titanium instruments exposed to high-concentration hypochlorite. J Endod. 2017;43(11):1847-1851.

[25] Bulem UK, Kececi AD, Guldas HE Experimental evaluation of cyclic fatigue resistance of four different nickel-titanium instruments after immersion in sodium hypochlorite and/or sterilization. J Appl Oral Sci. 2013;21(6):505-510.

[26] Al-Jamell D, Al-Nasrawi S, Al-Quraine N,et al. The effectiveness of three different methods for sterilization of the endodontic files (an in vitro study). Advances in Life Science and Technology.2014;27(4-:1-6.

[27] Thompson S An overview of nickel-titanium alloys used in dentistry. Int Endod J. 2000;33 (4):297-310.

[28] Abu-Tahun IH, Kwak SW, Ha J-H, et al. Microscopic features of fractured fragment of nickel-titanium endodontic instruments by two different modes of torsional loading. Scan 2018;2018.

[29] Cheung G, Peng B, Bian Z, et al. Defects in ProTaper S1 instruments after clinical use: fractographic examination. Int Endod J. 2005;38(11):802-809.

[30] Plotino G, Costanzo A, Grande NM, et al. Experimental evaluation on the influence of autoclave sterilization on the cyclic fatigue of new nickel-titanium rotary instruments. J Endod. 2012;38(2):222-225.

[31] Zhao D, Shen Y, Peng B, et al. Effect of autoclave sterilization on the cyclic fatigue resistance of thermally treated Nickel-Titanium instruments. Int Endod J. 2016;49(10):990-995.

[32] Özyürek T, Yllmaz K, Uslu G The effects of autoclave sterilization on the cyclic fatigue resistance of ProTaper Universal, ProTaper Next, and ProTaper Gold nickel-titanium instruments. Restor Dent Endod. 2017;42(4):301-308.

[33]. Hilfer PB, Bergeron BE, Mayerchak MJ, et al. Multiple autoclave cycle effects on cyclic fatigue of nickel-titanium rotary files produced by new manufacturing methods. J Endod. 2011;37(1):72-74.

[34] Sattar J, Abdul-Zahra Al Hmedat Z-N. Comparison of cyclic fatigue among protapergold, one curve, wave one gold and vdw blue files. Biochem Cell Arch 2019;19 (1):1309-1312.

[35] Haïkel Y, Serfaty R, Bateman G, et al. Dynamic and cyclic fatigue of engine-driven rotary nickel-titanium endodontic instruments. J Endod. 1999;25(6):434-440.

[36] Shen Y, Stojicic S, Qian W, et al. The synergistic antimicrobial effect by mechanical agitation and two chlorhexidine preparations on biofilm bacteria. J Endod. 2010;36(1):100-104.

[37] Jr JF S, Rôças IN, Favieri A, et al. Chemomechanical reduction of the bacterial population in the root canal after instrumentation and irrigation with $1 \%, 2.5 \%$, and $5.25 \%$ sodium hypochlorite. J Endod. 2000;26(6):331-334.

[38] Retamozo B, Shabahang S, Johnson N, et al. Minimum contact time and concentration of sodium hypochlorite required to eliminate Enterococcus faecalis. J Endod. 2010;36 (3):520-523. 
[39]. Berber V, Gomes B, Sena N, et al. Efficacy of various concentrations of $\mathrm{NaOCl}$ and instrumentation techniques in reducing Enterococcus faecalis within root canals and dentinal tubules. Int Endod J. 2006;39(1):10-17.

[40] Vianna ME, Gomes BP Efficacy of sodium hypochlorite combined with chlorhexidine against Enterococcus faecalis in vitro. Oral Surg, Oral Med, Oral Pathol, Oral Radiol, Endodontol. 2009;107(4):585-589.

[41] Gomes B, Ferraz C, ME V, et al. In vitro antimicrobial activity of several concentrations of sodium hypochlorite and chlorhexidine gluconate in the elimination of Enterococcus faecalis. Int Endod J. 2001;34(6):424-428.

[42] Clegg M, Vertucci F, Walker C, et al. The effect of exposure to irrigant solutions on apical dentin biofilms in vitro. J Endod. 2006;32(5):434-437.

[43]. Gulsahi K, Tirali RE, Cehreli SB, et al. The effect of temperature and contact time of sodium hypochlorite on human roots infected with Enterococcus faecalis and Candida albicans. Odontology. 2014;102(1):36-41.

[44] Berutti E, Angelini E, Rigolone M, et al. Influence of sodium hypochlorite on fracture properties and corrosion of ProTaper rotary instruments. Int Endod J. 2006;39 (9):693-699.

[45] Volume AH 19: fatigue and Fracture. ASM International. Online Edition, Materials Park, USA. 1996.

[46] Shen Y, Zhou H-M, Zheng Y-F, et al. Current challenges and concepts of the thermomechanical treatment of nickel-titanium instruments. J Endod. 2013;39(2):163-172.

[47] Abuhulaibah HF, AbuMostafa A Resistance to cyclic fatigue of nickel-titanium files immersed in sodium hypochlorite at body temperature. Int J Dentistry. 2020;2020.

[48] Topçuoğlu HS, Topçuoğlu G, Ö K, et al. Effect of two different temperatures on resistance to cyclic fatigue of one Curve, EdgeFile, HyFlex CM and ProTaper next files. Austral Endodontic J. 2020;46(1):68-72.

[49]. Bedier MM, Gawdat SI Effect of different temperatures on flexural cyclic fatigue resistance of 2shape and OneShape rotary endodontic instruments. Egyptian Dental J. 2020;66 (1)):355-364.

[50]. Demiral M, Keskin C, Inan U Effect of sodium hypochlorite activated by heating on the cyclic fatigue resistance of one-shape rotary instruments. J Dent App. 2017;4(1):372-375.

[51]. Pedullà E, Giusy Rita Maria La Rosa MSA, Gaetano I, et al. Effects of simultaneous liquid or gel sodium hypochlorite irrigation on the cyclic fatigue of two single-file nickel-titanium instruments. Appl Sci. 2020;10(6666):10.

[52]. Sarkar N, Redmond W, Schwaninger B, et al. The chloride corrosion behaviour of four orthodontic wires. J Oral Rehabil. 1983;10(2):121-128

[53]. Oshida Y, Sachdeva RC, Miyazaku S Microanalytical characterization and surface modification of TiNi orthodontic archwires. Biomed Mater Eng. 1992;2(2):51-69.

[54]. Dash T, Mohan RP, Mannava Y, et al. Effect of storage temperature and heating on the concentration of available chlorine and $\mathrm{pH}$ of $2.5 \%$ sodium hypochlorite. Saudi Endod J. 2017;7(3):161.

[55]. Kandaswamy D, Venkateshbabu N. Root canal irrigants. J Conservative Dentistry: JCD. 2010;13(4):256.

[56]. Prawoto Y, Ibrahim K, Wan NW. Effect of $\mathrm{pH}$ and chloride concentration on the corrosion of duplex stainless steel. Arab J Sci Eng. 2009;34(2):115.

[57]. Sadeghimeresht E, Reddy L, Hussain T, et al. Chlorine-induced high temperature corrosion of HVAF-sprayed Ni-based alumina and chromia forming coatings. Corros Sci. 2018;132:170-184.

[58]. Alapati SB, Brantley WA, Svec TA, et al. SEM observations of nickel-titanium rotary endodontic instruments that fractured during clinical use. J Endod. 2005;31(1):40-43.

[59]. Valois CR, Silva LP, Azevedo RB Multiple autoclave cycles affect the surface of rotary nickel-titanium files: an atomic force microscopy study. J Endod. 2008;34(7):859-862. 
[60]. ME K, ID C, Ertas H, et al. Comparative evaluation of cyclic fatigue resistance of four different nickel-titanium rotary files with different cross-sectional designs and alloy properties. Clin Oral Investig. 2017;21(5):1527-1530.

[61]. Braga LCM, Silva ACF, Buono VTL, de Azevedo Bahia MG. Impact of heat treatments on the fatigue resistance of different rotary nickel-titanium instruments. J Endod. 2014;40 (9):1494-1497.

[62]. Capar ID, Kaval ME, Ertas H, et al. Comparison of the cyclic fatigue resistance of 5 different rotary pathfinding instruments made of conventional nickel-titanium wire, M-wire, and controlled memory wire. J Endod. 2015;41(4):535-538.

[63]. Yao JH, Schwartz SA, Beeson TJ Cyclic fatigue of three types of rotary nickel-titanium files in a dynamic model. J Endod. 2006;32(1):55-57. 